\title{
PERAN KETEPATAN JOB DESCRIPTION TERHADAP KINERJA KARYAWAN PADA PT.JAYA BAKTI RAHARJA SUKABUMI
}

\author{
Muhamad sandria ${ }^{1}$, Acep Samsudin ${ }^{2}$, Kokom Komariah ${ }^{3}$ \\ ${ }^{1,2,3}$ Fakultas Ilmu Administrasi Bisnis dan Humaniora, Universitas Muhammadiyah Sukabumi \\ Email: sandriamuhamad11@ummi.ac.id ${ }^{1}$, acepsamsudin@ ummi.ac.id ${ }^{2}$, \\ ko2mpuspa@ummi.ac.id
}

\begin{abstract}
Intisari
Penelitian ini bertujuan untuk mengetahui peran Deskripsi Pekerjaan terhadap kinerja karyawan pada PT. Jaya Bakti Raharja Kota Sukabumi dengan waktu penelitian dilakukan pada bulan Maret 2020. Variabel dalam penelitian ini menggunakan deskripsi pekerjaan sebagai X dan kinerja karyawan sebagai Y. Metode dalam penelitian ini menggunakan metode kuantitatif dengan analisis regresi sederhana untuk teknik analisis data, dengan kuesioner yang dibagikan kepada 36 karyawan dengan populasi PT. Jaya Bakti Raharja. Dan hasil penelitian ini menunjukkan bahwa deskripsi pekerjaan mempengaruhi kinerja karyawan sebesar $21,3 \%$ dan memiliki pengaruh yang signifikan.
\end{abstract}

Kata Kunci : Job Deskripsi, Kinerja Karyawan

\begin{abstract}
This study aims to determine the role of Job Description on employee performance at PT. Jaya Bakti Raharja Sukabumi City with the time of the study was conducted in March 2020. The variables in the study used Job description as $X$ and employee performance as $Y$. The method in this study uses quantitative methods with simple regression analysis for data analysis techniques, with questionnaires distributed to 36 employees with a population of PT. Jaya Bakti Raharja. And the results of this study indicate that job description influences employee performance by $21.3 \%$ and has a significant effect.
\end{abstract}

Kata Kunci : Job description, employee performance

\section{PENDAHULUAN}

Dunia kerja sekarang ini sangat penting keberadaannya bagi masyarakat baik itu yang menengah kebawah ataupun yang menengah keatas dalam status sosialnya. Karena dengan dunia keja ini masyarakat dapat menggantungkan pengharapan penghasilan yang di dapatkan setiap waktu yang ditentukan untuk kebutuhan kedepannya. Didalam dunia kerja yang menjadi penopanang utamnya yaitu sumber daya manusianya itu sendiri.

Sumber Daya Manusia (SDM) ini suatu individu yang bekerja sebagai penggerak utama dalam suatu organisasi atau perusahaaan, dan bisa dikatakan SDM ini sebagai aset perusahaan, yang mana aset tersebut perlu dilatih dan dikembangkan keahlian dibidangnya agar sesuai dengan tujuan perusahaan. Yang tentunya dengan memiliki aset yang sesuai dengan kebutuhan perusahaan maka akan memudahkan perusahaan mencapat tujuannya begtitupun sebaliknya. Karena kunci keberhasilan suatu perusahaan itu dilihat dari kemampuan sumber daya manusianya.dibandingkan dengan sumber daya lainnya, Sumber daya manusia ini merupakan nomor satu dalam setiap kegiatan perusahaan karena jika tidaak adanya sumber daya manusia perusahaan tersebut tidak akan dapat memproduksi apapun tanpa ada penggerak utamanya. Kemudian sumber daya manusia ini perlu dilihat dari kinerjanya di dalam perusahaan apakah sudah sesuai atau belum dengan apa yang menjadi tanggung jawabnya di dalam perusahaan tersebut.

Kinerja karyawan ini sifatnya individual, karena dari setiap individu tersebut memiliki batas kemampuan ataupun keahliannya masing-masing dalam bekerja sehingga pihak perusahaan jangan memaksakan tugas atau pekerjaan yang tidak dikuasainya agar tidak keluar 
dari rencana perusahaan nantinya. Dan pihak perusahaanpun dapat mengukur kinerja karyawannya atas hasil kerjanya yang di capai apakah sudah sesuai atau belum dengan yang perusahaan harapkan. Karena kinerja ini hasil kerja nyata yang telah dilakukan karyawan didalam perusahaan tersebut. Dalam mengukur kinerja karyawan ini salah satunya bisa dilihat dari posisi pekerjaannya ataupun job descriptionnya masing masing.

Job description atau uraian jabatan ini ialah suatu gambaran pekerjaan apa yang akan menjadi tanggung jawabnya di dalam perusahaan tersebut dan menjadi pernyataan tertulis yang dikeluarkan oleh perusahaan, Job description ini memaparkan akan apa saja yang menjadi tanggung jawabnya dimulai dari target perusahaan, ataupun ketentuan -ketentuan lainnya, agar tidak menyimpang dan menggerjakan tugas yang bukan menjadi tanggung jawabnya karena biasanya itu diluar kemampuan karyawan tersebut. Apabila Job description ini sudah tersusun dan terlaksana dengan baik akan mudahnya mencapai tujuan perusahaan secara luas.

Salah satu perusahaan dengan adanya Job description didalam perusahaan tersebut yaitu PT. Jaya Bakti Raharja. PT Jaya Bakti Raharja Cabang Sukabumi ini merupakan perusahaan industri dan bergerak di bidang distributor tolak angin, freshcare,dan lain-lain. Didalam perusahaan ini terdapat sumber daya manusia dengan job descriptionnya masing-masing dan terletak di Kota Sukabumi Jl. Letda Asmita Blok D2 no 82. Dari penjelasan diatas peneliti ingin mengukur sejauh mana peran job description di dalam suatu perusahaan terhadap kinerja karyawan, maka dari itu penulis berinisiatif mengambil judul penelitian ini dengan judul "Peran Ketepatan Job Description terhadap Kinerja Karyawan pada PT Jaya Bakti Raharja"

\section{KAJIAN PUSTAKA \\ Job Description}

Deskripsi jabatan atau Job description adalah suatu pernyataan tertulis yang dikeluarkan perusahaan untuk menjelaskan tugas-tugas, fungsi, tanggung jawab, wewenang, dan aspekaspek pekerjaan tertentu lainnya dalam menentukan pekerjaan karyawan nantinya (Pattisahusiwa, 2017). Deskripsi Jabatan dapat diartikan juga dengan keperluan pimpinan dan karyawan di dalam perusahaan untuk melaksanakan pekerjaan, tugas serta kegiatan sesuai dengan porsinya masing-masing (Pitaloka, Mulyatini, \& Kasman, 2019). Uraian pekerjaan (jobdescription) merupakan suatu catatan yang dikeluarkan perusahaan yang sistematis tentang fungsi tugas, wewenang dan tanggung jawab dalam suatu jabatan tertentu, dengan diartikan berdasarkan fakta yang ada. Job Description ini harus menjelaskan agar dapat berfokus ataupun berkonsentrasi pada pekerjaan itu sendiri (Recky, 2018). Dimensi Job Description : 1)wewenang dalam bekerja 2)tanggung jawab dalam bekerja 3) Kondisi dalam bekerja 4)Fasilitas dalam bekerja serta 5)Standar hasila dalam bekerja

\section{Kinerja Karyawan}

Kinerja Karyawan adalah hasil kerja karyawan yang telah dicapai individu atau kelompok, sesuai dengan wewenang/tanggung jawabnya masing-masing karyawan (Jauvani, 2017). Kinerja merupakan hasil dari pekerjaan secara kualitas dan kuantitas yang telah dicapai oleh individu atau kelompok dalam melaksanakan tugas atau pekerjaannya sesuai dengan tanggung jawab yang diberikan kepadanya (Agustin, 2019). Kinerja ini dapat didefinisikan juga sebagai pengrefleksian seberapa baik karyawan dalam memenuhi persyaratan untuk sebuah pekerjaan. Kinerja seseorang merupakan hal yang bersifat individual dengan kemampuannya yang berbeda dan tugas yang berbeda pula. Pihak manajemen dapat mengukur hasil dari kinerja karyawan atas unjuk kerjanya berdasarkan hasilnya masing-masing (Damayanti, Hanafi, \& Cahyadi, 2018). Dimensi dari kinerja karyawan ini yaitu :1) Kualitas hasil kerja 2) Kuantitas Hasil Kerja 3)Ketepatan waktu 4)Kemampuan bekerja (Damayanti, Hanafi, \& Cahyadi, 2018). 


\section{PENGEMBANGAN HIPOTESIS}

Job Description ternyata mampu meningkatkan kinerja karyawan dengan memfokuskan dalam hak pemberian wewenang terhadap karyawan, kemudian tanggungjawab yang sesuai dan tidak melebihi batas kemampuan, karena dengan tanggung jawab yang sesuai dengan apa yang menjadi kenyamanannya dalam bekerja itu menjadi faktor acuan tercapainya kinerja karyawan yang baik dan sesuai (Pattisahusiwa, 2017).

H1 : Job description dan Job Specification berpengaruh positif dan signifikan terhadap kinerja karywan

Dengan berjalannya job description yang sesuai dengarn ruang lingkup didalamnya seperti fasilitas kerja yang di berikan perusahaan sesuai dengan kenyamanan karyawan kemudian kondisi pekerjaan yang nyaman dengan meminimalisir segala konflik internal maupun eksternal, dan standar hasil kerja tidak dilebih-lebihkan maka beberapa hal tersebut sangat mempengaruhi kondisi pekerjaan. dengan berjalannya beberpa dimensi yang menjadi faktor pendorong job description ini, maka kinerja karyawanpun akan semakin meningkat (Pitaloka et al., 2019).

\section{H2 : Job description berpengaruh positif dan signifikan terhadap kinerja karyawan}

Aktivitas Job description sebuah upaya dalam menciptakan kualitas dari pekerja dalam melakukan pekerjaan didalam perusahaan. Perusahaan akan memberikan timbal balik yang baik jika sumber daya manusia didalamnya telah mampu melaksanakan pekerjaan dengan sesuai dan jelas. jabatan didalam perusahaan perlu diadakan agar dapat mendesain organisasi dan menetapkan pembagian pekerjaan yang sesuai (Nurhayati, Chahyono, \& Herminawaty, 2017). H3 : Job description dan produktivitas kerja berpengaruh positif dan signifikan terhadap kinerja karywan

\section{METODE PENELITIAN}

Metode dalam penelitian dalam penelitian ini menggunakan kuantitatif dengan metode asosiatif untuk mengetahui pengaruh ataupun peran job description terhadap kinerja karyawan. atau untuk mengetahui pengaruh antara variabel bebas terhadap variabel terikat serta menggunakan IBM SPSS Statistic version 23 sebagai alat untuk melakukan penghitungan statistik. Untuk objek penelitiannya yaitu job description (x) kinerja karyawab (y). Dengan teknik pengumpulan data yang digunakan yaitu observasi dan kuisioner dengan skala pengukuran yang digunakan yaitu skala likert yang memiliki tingkatan jawaban yaitu $1=$ sangat tidak setuju, 2 = tidak setuju, 3 = cukup setuju, $4=$ setuju dan $5=$ sangat setuju.

Pada penelitian ini populasi yang ditetapkan oleh peneliti yaitu karyawan PT. Jaya Bakti Raharja yang berada di Kota Sukabumi. Jumlah sampelnya yaitu 36 karyawan atau responden. Dalam menghasilkan data yang lebih akurat peneliti menggunakan uji validitas dan uji reliabilitas. Serta teknik analisis data yang digunakan dalam penelitian ini yaitu uji normalitas kolmolgrov smirnov, koefisien korelasi, koefisien determinasi, regresi linear sederhana dan uji $\mathrm{t}$ atau uji hipotesis secara parsial.

\section{HASIL DAN PEMBAHASAN}

Tabel 1.1 Hasil Uji Validitaas X dan Y

\begin{tabular}{|c|c|c|c|c|}
\hline Variabel & R hitung & R tabel & sig & hasil \\
\hline $\mathbf{X 1}$ & 0.398 & 0.329 & 0.000 & VALID \\
\hline $\mathbf{X 2}$ & 0.679 & 0.329 & 0.000 & VALID \\
\hline $\mathbf{X 3}$ & 0.582 & 0.329 & 0.000 & VALID \\
\hline $\mathbf{X 4}$ & 0.547 & 0.329 & 0.000 & VALID \\
\hline $\mathbf{X 5}$ & 0.452 & 0.329 & 0.000 & VALID \\
\hline
\end{tabular}




\begin{tabular}{|c|c|c|c|c|}
\hline Variabel & R hitung & R tabel & sig & hasil \\
\hline Y1 & 0.491 & 0.329 & 0.000 & VALID \\
\hline Y2 & 0.823 & 0.329 & 0.000 & VALID \\
\hline Y3 & 0.683 & 0.329 & 0.000 & VALID \\
\hline Y4 & 0.604 & 0.329 & 0.000 & VALID \\
\hline
\end{tabular}

Sumber : Diolah peneliti, 2019

Berdasarkan data diatas dapat disimpulkan bahwa seluruh nilai pada variabel $\mathrm{x}$ ( job description) dan y (kinerja karyawan) menyatakan bahwa nilai $r_{\text {hitung }}>r_{\text {tabel }}$, maka dari itu seluruh item pertanyaan dalam penelitian ini dapat dinyatakan valid.

Tabel 1.2 Hasil Uji Reliabilitas X Dan Y

\begin{tabular}{|c|c|c|c|c|c|}
\hline \multicolumn{3}{|c|}{ Reliability Statistics $x$} & \multicolumn{3}{|c|}{ Reliability Statistics y } \\
\hline $\begin{array}{c}\text { Cronbach's } \\
\text { Alpha }\end{array}$ & $\begin{array}{c}\text { Cronbach's } \\
\text { Alpha Based } \\
\text { on } \\
\text { Standardized } \\
\text { Items }\end{array}$ & $\mathrm{N}$ of Items & $\begin{array}{c}\text { Cronbach's } \\
\text { Alpha }\end{array}$ & $\begin{array}{c}\text { Cronbach's } \\
\text { Alpha Based } \\
\text { on } \\
\text { Standardized } \\
\text { Items }\end{array}$ & $\mathrm{N}$ of Items \\
\hline ,361 & ,367 & 5 & ,536 & ,546 & 4 \\
\hline
\end{tabular}

Sumber : Diolah peneliti, $2019 \quad$ Sumber : Diolah peneliti, 2019

Hasil uji reliabilitas $\mathrm{x}$ dan y pada penelitian ini yaitu $\mathrm{x}$ ( Job description) $0.367>0.6$ dan y (kinerja karyawan ) 0.546>0.6 menyatakan bahwa seluruh nilai lebih besar dari nilai cronbach's alpha. Maka dapat diartikan bahwa seluruh variabel dinyatakan reliabel dan layak untuk menjadi alat ukur untuk analisis selanjutnya.

Tabel 3. Hasil Uji Normalitas Kolmolgrov Smirnov

\begin{tabular}{llr}
\hline \multicolumn{2}{c}{ One-Sample Kolmogorov-Smirnov Test } \\
\hline $\mathrm{N}$ & $\begin{array}{c}\text { Unstandardized } \\
\text { Residual }\end{array}$ \\
\hline Normal Parameters ${ }^{\mathrm{a}, \mathrm{b}}$ & Mean & 36 \\
& Std. Deviation &, 0000000 \\
Most Extreme Differences & Absolute & 1,49049177 \\
& Positive &, 112 \\
& Negative &, 112 \\
Test Statistic &,- 107 \\
Asymp. Sig. (2-tailed) &, 112 \\
\hline a. Test distribution is Normal. &, $200^{\text {c,d }}$ \\
b. Calculated from data. & \\
c. Lilliefors Significance Correction. \\
d. This is a lower bound of the true significance. \\
\hline Sumber: Data diolah peneliti, 2020
\end{tabular}

Sumber: Data diolah peneliti, 2020

Berdasarkan hasil data tabel Normalitas Kolmlgrov smirnov diatas menunjukkan bahwa nilai signifikannya yaitu 0.200 yang artinya bahwa $0.200>0.05$. maka dalam penelitian ini dapat dikatakan berdistribusi dan pengambilaan data dari populasi berjalan normal. 


\section{Tabel 4. Hasil Koefisien Korelasi}

\begin{tabular}{|c|c|c|c|}
\hline \multicolumn{4}{|c|}{ Correlations } \\
\hline & & Job Description & $\begin{array}{c}\text { Kinerja } \\
\text { Karyawan }\end{array}$ \\
\hline \multirow[t]{3}{*}{ Job description } & Pearson Correlation & 1 &, $461^{* *}$ \\
\hline & Sig. (2-tailed) & & ,005 \\
\hline & $\mathrm{N}$ & 36 & 36 \\
\hline \multirow[t]{3}{*}{ Kinerja Karyawan } & Pearson Correlation &, $461^{* *}$ & 1 \\
\hline & Sig. (2-tailed) &, 005 & \\
\hline & $\mathrm{N}$ & 36 & 36 \\
\hline
\end{tabular}

Sumber: Data diolah peneliti, 2020

Data dari koefisien korelasi ini menunjukan nilai signifikan sebesar 0.005 yang artinya lebih kecil dari 0.05. dari situ dapat diketahui bahwa ada hubungan antara job description terhadap kinerja karyawan. Dan untuk nilai pearson correlation pada penelitian ini sebesar 0.461 yang artinya terdapat hubungan yang cukup kuan antara jobdes terhadap kinerja karyawan.

\section{Tabel 5. Hasil Koefisien Determinasi}

\begin{tabular}{|c|c|c|c|c|}
\hline \multicolumn{5}{|c|}{ Model Summary } \\
\hline Model & $\mathrm{R}$ & R Square & $\begin{array}{l}\text { Adjusted R } \\
\text { Square }\end{array}$ & $\begin{array}{l}\text { Std. Error of the } \\
\text { Estimate }\end{array}$ \\
\hline 1 &, $461^{\mathrm{a}}$ & ,213 & ,189 & 1,51225 \\
\hline
\end{tabular}

Sumber: Data diolah peneliti, 2020

Berdasarkan data dari tabel diatas nilai $\mathrm{R}$ square sebesar 0.213 atau dalam bentuk presentase sebesar 21.3\%. Maka dapat diartikan bahwa adanya peran job description terhadap kinerja karyawan pada PT. Jaya Bakti Raharja sebesar 21.3\% dan 78,7\% dipengaruhi oleh berbagai variabel lain diluar penelitian ini.

\section{Tabel 6. Hasil Regresi Linear Sederhana}

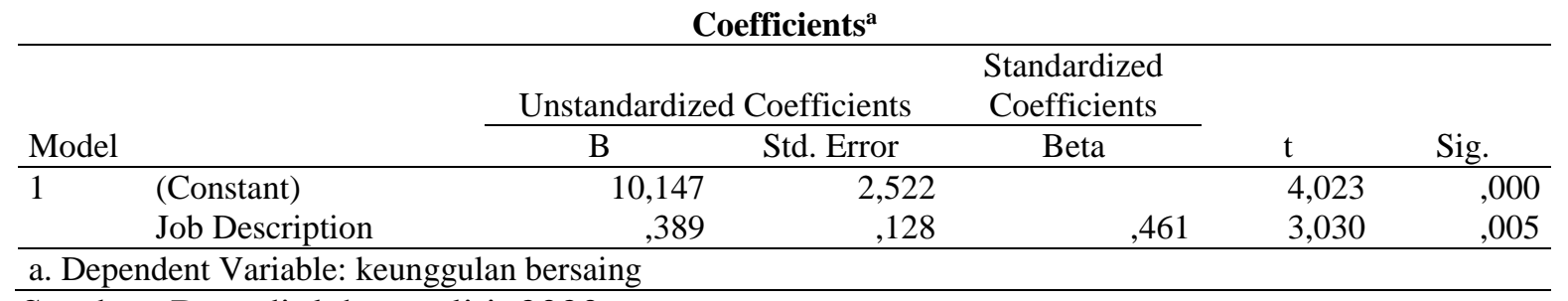

Sumber: Data diolah peneliti, 2020

Berdasarkan hasil data diatas dapat diperoleh nilai konstanta (a) $=7.377$ dan $b=0.613$ yang dapat disematkan kedalam rumus regresi linear sederhana menurut (Muntaha \& Sutrisna, 2018) yaitu sebagai berikut:

$\mathrm{Y}=\mathrm{a}+\mathrm{bX}$

$Y=10.147+0.389 X$ 
Dapat disimpulkan bahwa nilai konstanta (a) sebesar 10.147 maka jika x nilainya nol maka keunggulan bersaing memiliki nilai sebesar 10.147. Adapun nilai regresi x (job description) adalah 0.389 dapat diartikan bahwa setiap peran job description sebesar satu satuan maka sekaligus akan meningkatkan nilai pada kinerja karyawan pula.

Tabel 7. Hasil Uji T (Uji Hipotesis secara Parsial)

\begin{tabular}{|c|c|c|c|c|c|c|}
\hline \multicolumn{7}{|c|}{ Coefficients $^{\mathbf{a}}$} \\
\hline \multirow[b]{2}{*}{ Model } & & \multicolumn{2}{|c|}{ Unstandardized Coefficients } & \multirow{2}{*}{$\begin{array}{c}\begin{array}{c}\text { Standardized } \\
\text { Coefficients }\end{array} \\
\text { Beta } \\
\end{array}$} & \multirow[b]{2}{*}{$\mathrm{t}$} & \multirow[b]{2}{*}{ Sig. } \\
\hline & & $\mathrm{B}$ & Std. Error & & & \\
\hline 1 & (Constant) & 10,147 & 2,522 & & 4,023 & ,000 \\
\hline 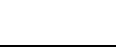 & Job description &, 389 &, 128 & ,461 & 3,030 &, 005 \\
\hline
\end{tabular}

Sumber: Data diolah peneliti, 2020

Hasil uji t dari tabel diatas dilakukan untuk menguji hipotesis dengan hasil niali thitung sebesar 3.030 dengan nilai signifikan pada tabel hasil penelitian tersebut sebesar 0.005 . Dengan nilai $t_{\text {tabel }}$ dapat diketahui dengan menggunakan rumus besaran derajat kebebasan (df) menurut (Muntaha \& Sutrisna, 2018) yaitu $\mathrm{t}_{\text {tabel }}=(\mathrm{df}=\mathrm{n}-\mathrm{k})$ maka $\mathrm{df}=36-1=35$. Dengan menggunakan distribusi $t_{\text {tabel }}$ dengan taraf 0.05 yaitu 1.6765. Maka dapat disimpulkan bahwa nilai $t_{\text {hitung }}$ lebih besar dari $t_{\text {tabel }}$ yaitu $3.030>1.6765$ dan nilai signifikan $0.005<0.05$ maka dari itu terdapat pengaruh antara job description terhadap kinerja karyawan.

\section{PEMBAHASAN}

Dari hasil pembahasan yang telah dilaukan peneliti diatas, telah didapatkan hasil analisis bahwa Job Description berpengaruh positif dan segnifikan terhadap knerja karyawa pada PT. Jaya bakti raharja. Hal tersebut dapat di buktikan setelah pengujian secara parsial (uji t). Terdapat berbagai macam jenis faktor yang mendukung dalam meningkatkan kinerja karyawan yang salah satunya yaitu meningkatkan fasilitas kantor yang ada, kemudian memberi porsi pekerjaan yang sesuai, memberikan waktu pekerjaan yang tepat, dan lain-lain. Seperti hasil dari penelitian yang dilakukan (Elan \& Kurniawan, 2018) menjelaskan bahwa Job description dalam suatu perusahaan sangat penting peranannya dengan adanya job description maka akan membantu setiap karyawan dalam mengarahkan pekerjaan menjadi lebih tepat dan teratur tentu dengan adanya dukungan dari perusahaan baik itu secara fisik amupun non fisik untuk mendukung setiap karyawan melakukan pekerjaannya dengan serius dan sesuai kaidah perusahaan. Maka dari itu job description berpengaruh positif tehadap kinerja karyawan pada PT.Jaya bakti raharja diterima dan teruji kebenarannya.

\section{KESIMPULAN}

Berdasarkan hasil dari penelitian ini, mengetahui hasil koefisien korelasi menyimpulkan bahwa terdapat pengaruh Job description terhadap kinerja karyawan pada PT. Jaya bakti raharja dan berkorelasi cukup kuat. Selain itu hasil dari koefisien determinasi menunjukkan pengaruh sebesar $21.3 \%$ serta sisanya $78.7 \%$ itu dipengaruhi variabel lain. Dan untuk pengujian secara parsial (uji $\mathrm{T}$ ) didapatkan hasil dengan nilai thitung lebih dari nilai tabel yang artinya job description berpengaruh signifikan terhadap kinerja karyawan. Maka dapat disimpulkan bahwa terdapat pengaruh job description terhadap kinerja karyawan pada karyawan PT. Jaya Bakti Raharja Sukabumi. 


\section{SARAN}

Berdasarkan hasil penelitian diatas maka peneliti menyarankan perusahaan PT. Jaya Bakti Raharja agar lebih memperhatiakan kebutuhan karyawan dalam bekerja serta mampu menempatkan karyawan sesuai dengan skillnya agar dapat mendapatkan hasil kerja yang maksimal nantinya selain itu juga memberikan porsi pekerjaan haarus sesuai dengan tugasnya di dalam perusahaan itu untuk membuat karyawan terjaga fokusnya dalam bekerja dan tau apa yang menjadi kewajibannya.

\section{REFERENSI}

Agustin, T. (2019). Analisis Pengaruh Gaya Kepemimpinan da Job description terhadap Kinerja Pegawai pada Kantor Badan Kepegawaian Daerah (BKD) Kabupaten Kediri. $J I M M U, I V($ September).

Damayanti, R., Hanafi, A., \& Cahyadi, A. (2018). Pengaruh Kepuasan Kerja Karyawan (studi kasus karyawan non medis RS Islam Siti Khadijah Palembang). Ilmiah Manajemen Bisnis Dan Terapan, (2), 75-86.

Elan, U., \& Kurniawan, I. (2018). Pengaruh Job Description Terhadap Kinerja Karyawan Departemen Security Di PT . Wilmar Nabati Indonesia - Gresik. Jurnal Fakultas Ekonomi, 03(X), 154-180.

Jauvani, E. (2017). Pengaruh Stres Kerja Terhadap Kinerja Karyawan : Studi Kasus pada Tenaga. Jurnal Ilmiahprodi Manajemen Universitas Pemulang, 4(1), 221-228.

Muntaha, A. S., \& Sutrisna, E. (2018). Pengaruh Strategi Diferensiasi Terhadap Loyalitas Konsumen Bisnis Jasa Pengiriman Pt. Pos Indonesia (Persero) Pekanbaru. Jom Fisip, $5(1), 5$.

Nurhayati, S., Chahyono, \& Herminawaty. (2017). Pengaruh Job Description Terhadap Produktivitas Kerja Pada Perusahaan PT Semen Tonasa IV Kabupaten Pangkep. Unibos Makasar, 3(012), 138-149.

Pattisahusiwa, S. (2017). Pengaruh Job Description Dan Job Specification Terhadap Kinerja Proses. Jurnal Akuntabel, 10(1), 57-65.

Pitaloka, K., Mulyatini, N., \& Kasman. (2019). “ Pengaruh Job Desription dan Job Satisfaction terhadap kinerja karyawan (Suatu Studi Pada PT. Pos Indonesia Cabang Ciamis)." 1, 42-58.

Recky. (2018). Pengaruh Description Terhadap Produktivitas kerja pada PT. Bumi Palma Lestari Persada Kecamatan Enok. Bappeda, 4(3), 136-141. 